REVISTA LEGEM

ISSN Online 2346-2787

\title{
La caida del wall street y el artículo 60 de la constitucion colombiana: crisis economica y enajenacion de acciones estatales
}

\section{The fall of Wall Street and Article 60 of the Colombian constitution: economic crisis and alienation of state shares}

\author{
iD \\ Zaidy Sánchez Niebles* \\ Universidad del Atlántico, Colombia \\ zsanchezn@est.uniatlantico.edu.co \\ Recibido: 07 de febrero de 2020/ Aceptado: 11 de julio de 2020
}

\section{Resumen}

\begin{abstract}
A lo largo de este artículo, se desarrolla la caída de la bolsa de valores de Nueva York en los años 30 la cual genero consecuencias en Latinoamérica en países como Colombia, donde en la nueva constitución de 1991 aparece el articulo 60 sobre enajenaciones de empresas del estado la cual podría ser clave a la hora de sanar la deuda externa del país adquirida con Estados Unidos.
\end{abstract}

Palabras clave: vacciones, crisis, depresión, enajenación, estado, economía, miedo.

\section{ABSTRACT}

Throughout this article, the fall of the New York stock exchange in the 1930s is developed, which generated consequences in Latin America in countries such as Colombia, where article 60 on disposals of companies in the This state could be key in healing the country's foreign debt acquired with the United States.

Keywords: actions, crisis, depression, alienation, state, economy, fear.

Como citar: Sánchez Niebles, Z. (2020). La caida del wall street y el artículo 60 de la constitucion Colombiana: crisis economica y enajenacion de acciones estatales. Revista LEGEM, 6(1). 99-112. https://doi.org/10.15648/legem.1.2020.2667

* Estudiante de modalidad de doble programa de la universidad del Atlántico, Colombia, perteneciente a las facultades de ciencias humanas, en el programa de historia, y ciencias jurídicas, en el programa de derecho. 


\section{Introducción}

En el marco económico mundial, el estado colombiano se encuentra con una deuda externa por sanear adquirida desde el siglo XX, si bien la gran solvencia económica que tenía estados unidos para antes del crack del 29 le permitía dar grandes créditos a países latinoamericanos como Colombia. Parte del desafío de este estado endeudado es encontrar las maneras más pertinentes y eficaces para pagar sus deudas externas, principalmente con el país norteamericano, entendiendo que una de ellas sería la aplicabilidad del artículo 60 de la constitución colombiana, es decir enajenar las empresas y acciones del estado para la mejora económica aunque a la hora de la práctica no sea así por los diversos conflictos de intereses que existen dentro del país.

la relación que tiene este suceso histórico, con la enajenación de acciones estatales por parte del estado colombiano, si bien se considera como manifestación esencial es el corte de crédito por parte de los bancos norteamericanos a Colombia, en la segunda mitad del año de 1928, un año antes de la gran depresión, y posteriormente la ciada de las ventas del café y el petróleo en el país, seguido que en el año de 1929, el país termino reflejando indicadores económicos seriamente angustiantes, no es un secreto la deuda externa que ha tenido Colombia con Estados Unidos, donde a pesar de los años de diferencias de un acontecimiento con el otro, como lo fue el del año 29 y la enajenación estatal en la nueva constitución colombiana en el año 91, siendo la segunda una forma de pagar deudas exteriores por medio de la venta de empresas u acciones del estado al sector privado, deudas que se adquirieron en una coyuntura donde la proliferación económica estadounidense era espectacular, y este no se limitaba a la hora de conceder crédito a países latinoamericanos, como es en el caso de Colombia.

Este artículo tiene como propósito profundizar la historia económica del siglo XX, entendiéndola como un estudio analítico y crítico del desarrollo financiero de los estados unidos para la década del 1929, y como todo llevo a la crisis del jueves negro, por lo cual permite apreciar como la capital económica del momento, proyectando hacia afuera el conflicto interno económico en el cual se encontraban sumergidos, donde sus efectos se tomaron a Latinoamérica, analizando el caso para Colombia, y el cambio de constitución en 1991 resaltando las ventas de las acciones y empresas del estado. La consulta de lecturas como las economías latinoamericanas 1929-1939, y el efecto de la gran depresión de 1929 en las economías de Perú y Colombia, entre otras, también el análisis de la prensa colombiana, el periódico el tiempo en la temporalidad de 1929 - 1932, y sobre toda la actual constitución vigente dentro del país, siendo todo lo anterior de gran importancia, porque permiten una amplia visión para comprender como fue el desarrollo económico antes, en y después de la gran depresión del 29, y sus consecuencias en estados latinoamericanos, como el caso de Colombia.

\section{Antecedentes.}

Las crisis económicas han estado presente a lo largo de la historia de la humanidad, cada una de ellas con efectos que cambian el comportamiento económico y sus relaciones, ya sean bien que se den por las guerras, mala administración, sobreproducción, escases, entre otras causas; pero ninguna crisis del siglo XX fue tan relevante a nivel mundial como la caída del Wall Street en los Estados Unidos de América, también conocido como el jueves negro, donde la población norteamericana tuvo un colapso económico, que destruyo no solo las finanzas sino también el modo de vida tan rico que se habían acostumbrado a tener, ya que era tanto la solvencia económica, que el acto de invertir en la bolsa paso de ser una actividad solo para hombres economistas, con grandes ingresos y dueños de empresas, a ser una actividad de interacción 
social, que podríamos comparar esta actividad con ir de compras a un centro comercial, ya que se contaban hasta con entidades no gubernamentales encargadas de dar crédito a las personas hasta de un $90 \%$ para comprar acciones en la bolsa de valores americana en Wall Street. La vida era tan rentable que nadie consideraba mínimamente que la depresión estaba más cerca de lo que se pensaba.

La vida americana estadounidense antes de la crisis era simplemente espectacular, se podría decir que la pobreza era mínima, el movimiento social que se dio para la época, pasar de la pobreza a tener grandes ingresos de dinero en cuestión de días, horas o minutos, hacían que hasta el limpia botas de los economista de la bolsa de valores del Wall Street, que al tener un contacto cercano con esos, y al escuchar sus conversaciones sobre finanzas e inversiones, aprendían sobre el movimiento de la bolsa y así pudieron mejorar su calidad de vida. Pero estas inversiones no solo estaban en manos delos hombres, sino también de las mujeres, fue tanto el boom de las acciones, que realizar esta acción se constituyó en una acción de costumbre por parte de todas las personas norteamericanas. El movimiento económico para entonces permitía que en New York, considerada la capital económica mundial, después del desplazamiento de Londres, se viviera de forma ostentosa por parte de sus ciudadanos, y que los temas de conversación fueran en torno a las finanzas, pero hay que destacar que se abrieron muchos bancos a raíz de la realidad económica del país, y hay algo claro que el dinero que se encontraba depositado en los bancos no era suficiente para responder las necesidades y lo expresado en las acciones de las personas que invertían en la bolsa de valores, más que todo el dinero era inexistente, no existía dinero efectivo impreso en papel moneda, lo que existía eran las garantías de las acciones.

Pero ¿qué fue en pocas palabras el Crack del 29? Fue la caída estrepitosa del valor de las acciones de las principales empresas públicas en la Bolsa de Valores de Nueva York, que se originó por los especulativos manejos financieros según investigaciones clásicas de este tema de los autores J. K. Galbraith y Ch. Kindleberger. Sin embargo el doctor González Molina sostiene que el verdadero factor que originó este desplome financiero fue un deterioro en las utilidades del sector industrial estadounidense (carbón, siderurgia, telégrafos, ferrocarriles y puertos). (Rodríguez, 2011).

Para ser más claros, cuando los inversionistas observaron el desplome financiero que se estaba dando, corrieron a vender sus acciones, a pedir el dinero del valor que tenían sus acciones antes de que la bolsa decayera por completo, pero al ser la inversión una costumbre social, que todas las personas hacían, por ende cuando todos querían recuperar sus dineros, los bancos colapsaron, ya que no tenían como soportar la demanda, donde el miedo y el pánico dio pie al jueves negro. Entonces, ¿Por qué el miedo fue un factor determinante para la crisis del 29?, personalmente considero que el miedo fue el sentimiento detónate para la gran depresión, las especulaciones generadas causaron que las personas sintieran pánico, por lo cual estas a su vez reaccionaron de una manera conjunta, y ¿Qué es lo primero que harías si te dicen que tus acciones están perdiendo su valor?, ¿venderlas?, ¿recuperar tu dinero?, bien todo esto llevo a que los americanos perdieran el control y solo pensaran en no perderlo todo.

The crash wiped people out. There were forced to sell businesses and cash in their life savings. Brokers called in their loans when the stock market started falling. People scrambled to find enough money to pay for their margins. They lost faith in Wall Street (Amadeo, 2020). Un factor que debemos resaltar es la falta de intervención del estado americano para la regulación de la economía y del movimiento bancario en la bolsa de valores de New York, lo cual permitió que cualquiera persona diera pie a jugar a ser economista, donde personas con intenciones inconstitucionales, estafaban a las personas que no contaban con un conocimiento económico, por lo cual generaron conflicto con la seguridad en la bolsa, aunque estos eran organismos ajenos a este. Donde después del pánico las acciones dejaron de tener valor, tanto que se podría decir que valían un dólar, es decir nada. 
Se preguntaran cual es la relación que tiene este suceso histórico, con la enajenación de acciones estatales por parte del estado colombiano, si bien se considera como manifestación esencial es el corte de crédito por parte de los bancos norteamericanos a Colombia, en la segunda mitad del año de 1928, un año antes de la gran depresión, y posteriormente la ciada de las ventas del café y el petróleo en el país, seguido que en el año de 1929, el país termino reflejando indicadores económicos seriamente angustiantes, no es un secreto la deuda externa que ha tenido Colombia con Estados Unidos, donde a pesar de los años de diferencias de un acontecimiento con el otro, como lo fue el del año 29 y la enajenación estatal en la nueva constitución colombiana en el año 91, siendo la segunda una forma de pagar deudas exteriores por medio de la venta de empresas u acciones del estado al sector privado, deudas que se adquirieron en una coyuntura donde la proliferación económica estadounidense era espectacular, y este no se limitaba a la hora de conceder crédito a países latinoamericanos, como es en el caso de Colombia.

La realidad del estado colombiano es que en los años noventa en el país colombiano se dan procesos de muchas reformas, pasamos de un estado de derecho a un estado social de derecho, teniendo como referente el cambio de constitución, para entonces nos encontrábamos arraigados a un pasado colonial y de dependencia a la iglesia católica, apostólica, romana. Todo esto llego a su fin con el cambio de constitución de 1886 por la actual de 1991.

En la constitución de 1991 el pueblo pasa a ser el constituyente primario, marcada por la desmovilización del grupo insurgente al margen de la ley, el M-19, esta carta se caracteriza por ser participativa, pluralista y por la clara división de las tres ramas de poder en el estado. La economía del país para este periodo de la historia, se había visto marcado por el proceso de privatización implementado desde los años ochenta, más que todo a mediados de este, para el momento Colombia se caracterizaba por ser un estado mucho más proteccionista a nivel económico, donde este se reservaba al ámbito público, pero con la liberación del mercado comercial, se iniciaron ventas de empresas y acciones mayormente en el sector industrial así como en el sector financiero.

Actualmente a nivel mundial hablar sobre una reserva en lo relacionado con la liberación comercial es ir en contra de la evolución de la economía, sabiendo que esta presenta las mejores oportunidades para un crecimiento en el mercado internacional, causando reformas profundas en la legislación de los países para generar una macroeconomía.

El principal elemento de participación privada se ha concretado en financiamiento, construcción y operación de proyectos de infraestructura, anteriormente ejecutados por el sector público. Lo anterior demuestra que si bien Colombia no siguió la estrategia de un proceso amplio y centralizado de privatización, sí ha seguido el ejemplo regional de abrir espacios considerables a la inversión privada. Los retos son grandes para reducir el papel del Estado en áreas donde el sector privado puede jugar un papel primordial y operar con una mayor eficiencia, y así los recursos y esfuerzos públicos pueden ser dirigidos a otras áreas prioritarias, en especial en los sectores sociales (Rafael, H. 1995)

Todas estas reformas presentaban los argumentos basados en el nuevo proceso de globalización que se estaba llevando a cabo para el momento, donde si Colombia quería mantenerse más allá del margen de la economía mundial, y empezar a pagar sus deudas externas, como con Norteamérica, de una manera más ágil, si es que pudiese considerarse de esa manera, debía ser veraz a la hora de su legislación económica, y así abrirse paso firme en el mercado mundial.

Todo esto nos indica cómo era la realidad a mediados del siglo XX, marcado por grandes acontecimientos económicos a nivel mundial. Encontrándose la primera y segunda guerra mundial, las cuales dilucidaron 
las grandes hiperinflaciones en los países cercanos y participantes en estos conflictos violentos, se genera como tal el estallido de los mercados internaciones de capital, originándose en los Estados Unidos de América y el inicio de las mayores crisis económicas, como lo fue la gran depresión.

Para el caso Colombiano encontramos la tan denominada, la danza de los millones, la cual como consecuencia trajo nuevamente al estado a la participación en los mercados internacionales por medio de capital, posteriormente de superar la etapa de relegado. Este a su vez se estuvo antecedido por esfuerzos que llevasen a la modernización de la administración pública y la organización del sistema a nivel monetario, la cual se llevó a cabo por las necesidades de vender al país de una manera atractiva a futuros extranjeros que pudiesen invertir en él.

\section{Efectos de la gran depresión en América Latina}

Se ha descrito habitualmente la depresión de 1929 como el momento decisivo de la transición de América Latina de un crecimiento económico hacia afuera, basado en la exportación, a un desarrollo hacia adentro, sostenido por la industrialización de sustitución de importaciones (Bulmer Thomas, 1990).Los efectos en Latinoamérica no tardaron en observarse, siendo estos de diferente índole, sus importaciones empezaron a recibir las consecuencias de la depresión, donde su valor en el mercado mundial decayó a nivel de las materias primas; consecutivamente se tenía que solventar la deuda adquirida por los prestamos estadounidenses, que se habían adquirido para que el progreso y la modernidad llegaran a Latinoamérica, pero la mayoría del dinero cayó en manos de los corruptos, mejor conocido como "la danza de los millones". No se tenía el dinero para pagar, donde este rebasaba el capital interno de los países latinoamericanistas, entrando así en años posteriores a la mora, casi en su totalidad. Para el caso argentino, este fue el país latinoamericano menos afectado por la depresión, ya que su producto per cápita, estaba en el mismo margen que manejaban los países del continente europeo.

El subcontinente latinoamericano tuvo que dar un viraje en su visión de desarrollo económico a raíz de la crisis de los años treinta dejando de ver a Europa como centro económico mundial para comenzar, de manera forzada, a ser más influido y dependiente de las decisiones económicas de los Estados Unidos. (Rodríguez, 2011). El hecho de que los países de América del sur no pudieran seguir pagando la deuda externa que habían contraído por los préstamos extranjeros llevo a que una gran parte de estos países decidieran no pagarla completamente; a pesar de esto se activaron de nuevo las economías, ya que estos países invirtieron parte de su capital, que está establecido para la cancelación de la deuda externa, en el aprovechamiento de su economía, básicamente en expandir sus producciones y el comercio interno. El gobierno estadounidense "tolero", en cierta medida, el no pago de los préstamos. Los países latinoamericanos lograron tener una autonomía financiera importante, pero en un futuro no muy lejano, después de la recuperación de la economía estadounidense, estos retomarían el cobro de la deuda para evitar que se volviera a dar una suspensión igual después de la crisis.

La política desarrollada en la industrialización como la sustitución de importaciones, se da después del desarrollo de todos estos hechos, como la manera para generar producciones a nivel interno de todos los bienes, en especial los del segundo sector económico, donde estos en su mayoría y de forma masiva eran importados de las potencias de la época, con la finalidad de reducir la dependencia financiera, para así poder tener un crecimiento económico no hacia fuera, sino hacia adentro, potenciar su propia economía latinoamericanista, motivados por el crack del 29, que se ocasiono a nivel mundial, pero que también dio paso a que los países reaccionaran ante el desamparo económico de América Latina. Se mantuvieron al 
margen del mercado financiero mundial por un lapso de tiempo determinado para poder readaptarse al mismo sistema de nuevo, y de igual manera por los obstáculos encontrados por los p9iases europeos para entrar de nuevo al mercado mundial. Como efecto de la gran depresión, en América Latina se expande la pobreza de una manera grave, aun mas de la que ya se encontraba existente en los piases antes de esta, en los países más afectados, pero países como Colombia, Brasil, México, Perú y Chile, pudieron incrementar su PIB, y aumentar su producción a nivel industrial. Estas graves consecuencias financieras causo pobreza, desempleo, malas condiciones de vidas, y un precario nivel de adquisición, y de igual manera un desprecio por el sistema imperialista estadounidense sobre la América del sur, manifestándose en corrientes socialistas, pero también no todo fue radical, también se observaron reacciones de tipo conservador, de las elites, para mantener sus relaciones con Estados Unidos.

Los años treinta en América Latina no pueden presentarse como una radical ruptura con el pasado, aunque la década tampoco representa una oportunidad perdida. En un contexto externo generalmente hostil, la mayoría de países lograron reconstruir su sector externo; casi todos expandieron la producción de artículos importables donde era factible, y acrecentaron la oferta de bienes y servicios no comercializables en el comercio exterior. (Bulmer Thomas, 1990, p. 46).

\section{Colombia antes y después de 1929}

Antes del estallido de la crisis contaba con un éxito en las exportaciones cafeteras, expansión ferroviaria y vial, contaba con grandes ingresos por parte de los mercados internacionales y por la indemnización por Panamá, entre otros movimientos sindicales y agrarios.

El primer efecto o consecuencia a observar fue la suspensión de los créditos, la caída del valor del café, lo que produjo una depresión en Colombia, Las exportaciones en el caso de Colombia cayeron en un 58\% de su pico más alto en 1928, y su punto más bajo en 1932 (Throp, 1988, p. 117), las exportaciones de Colombia disminuyeron en $\$ 200.000$, los bonos en la bolsa de valores de Nueva York, cayeron, por ende fue imposible que se pudiese obtener nuevas prestaciones. El gobierno de Enrique Olaya Herrera fue el que tuvo que afrontar la dura depresión aparte de eso también sucesos como el conflicto colombo - peruano, Por ende, después de observar las consecuencias negativas que se adquirieron por proyección de la gran depresión de los Estados Unidos, se adoptó una nueva protección económica por medio de aranceles, con la finalidad de proteger la agricultura y la industrialización nacional. Se genera la creación de la caja agraria, el banco central hipotecario y la corporación colombiana de crédito.

A causa del paro del flujo de crédito externo, en el país por falta de capital, se paralizaron obras de construcción, por tal motivo los trabajadores fueron despedidos, y se descendieron los precios, a nivel interno los bancos comerciales y los hipotecarios que se encontraban en funciones en diferentes departamentos del país, tuvieron un duro golpe por la falta de inyección del dinero proveniente del crédito externo.

Años después de la gran depresión, después de romper con el statu quo, el mercado colombiano se vio impulsado por el proceso de industrialización, por medio de la reducción de costos, el aumento de la economía a gran escala, se cambia la metodología en el aprendizaje por medio de la praxis, la aglomeración económica y la trasformación gracias al desarrollo tecnológico. La industria manufacturera colombiana, surge gracias a la gran trasformación a nivel financiero económico. La producción en manos de obreros, o mano de obra, se relacionó directamente con el status del capital humano y fisiológico. 
Imagen 1. fracción del periódico el tiempo (1930) sobre el intercambio comercial entre Colombia y los Estados Unidos, en la sección comercial y de finanzas.

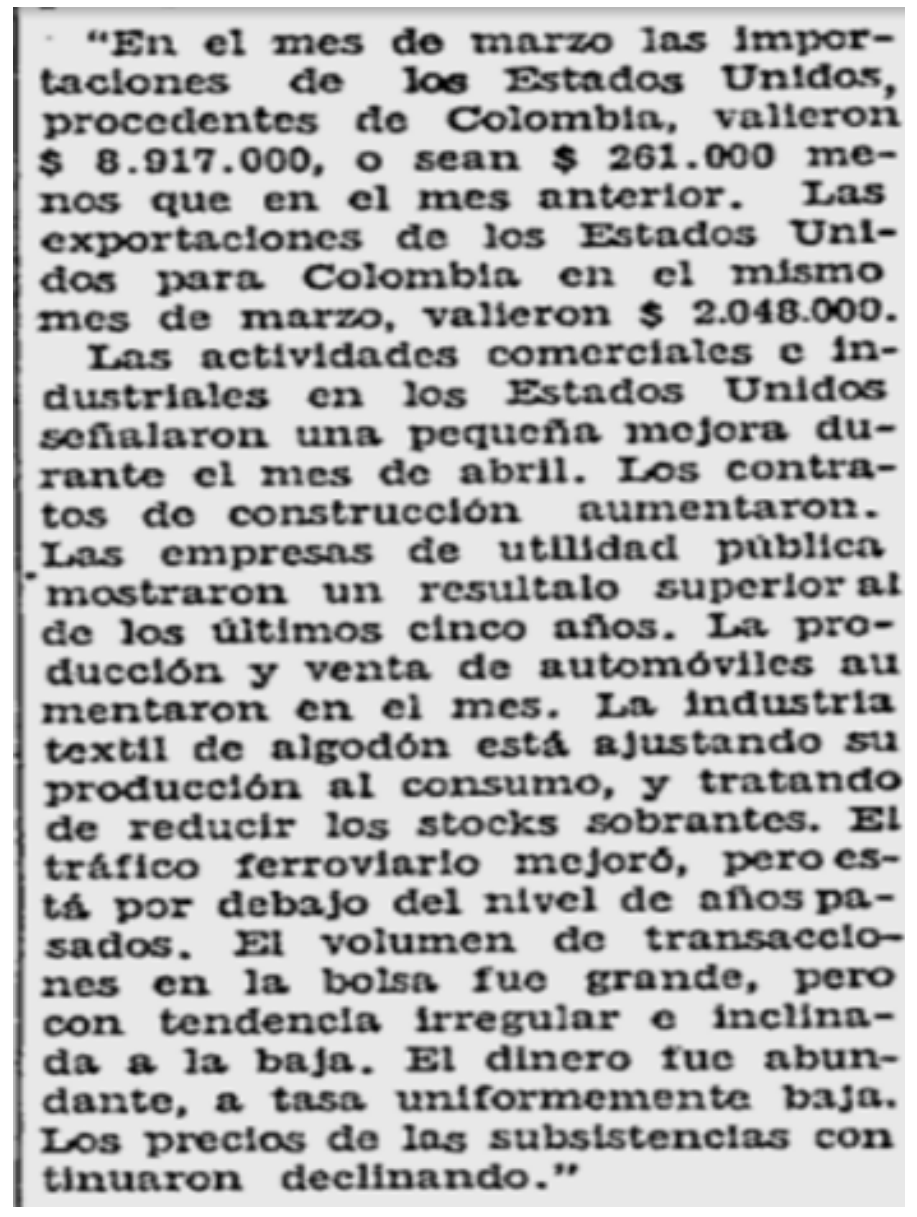

\section{Enajenación estatal y el acceso a la propiedad}

En la constitución Colombiana, en el título 2, De los derechos, las garantías y los deberes, encontramos en el capítulo 2, De los derechos sociales, económicos y culturales, el artículo 60. Este se define de la siguiente manera:

\footnotetext{
“El Estado promoverá, de acuerdo con la ley, el acceso a la propiedad. Cuando el Estado enajene su participación en una empresa, tomará las medidas conducentes a democratizar la titularidad de sus acciones, y ofrecerá a sus trabajadores, a las organizaciones solidarias y de trabajadores, condiciones especiales para acceder a dicha propiedad accionaria. La ley reglamentará la materia".
}

Este artículo constitucional se encuentra desarrollado en la ley 226 de 1995, avalado por consejo de ministros, su objetivo principal es encargarse que las acciones por parte del estado sean enajenadas, es decir, vendidas, donadas o cedidas a la mayor cantidad de personas posibles, sean extranjeras o nacionales, pero con la condición de priorizar el acceso de estas acciones a los sectores solidarios, el cuidado del patrimonio público y buscar que aquellas empresas que presten servicios públicos y operen con recursos públicos, cuando sean enajenas, puedan seguir funcionando de una manera eficaz en la prestación de sus servicios para la nación posteriormente a la privatización. 
Este proceso de enajenación tiene básicamente dos etapas, primeramente se le ofrece a los sectores solidarios las acciones de manera exclusiva por un acumulado de 60 días con facilidades de pago con crédito, si para entonces no se da inicio al proceso se colocara para que otros inversionistas, con un precio de igual o mayor cuantía puedan comprar, siempre manteniendo la libre concurrencia y publicidad.

Actualmente el estado cuenta con participación en 105 empresas en todo el país, estas se encuentras operando en diferentes sectores la economía, pero las carteras se encuentran repartidas de manera desproporcional entre los ministerios, Ministerio de Transporte cuenta con 34, de Hacienda 29, agro 13 y TIC 10, en Minas y Salud 4, en Comercio e Interior 3, Vivienda 2; y en Trabajo y Departamento Nacional de Planeación 1.

Esta ley es aplicada, según el artículo 1 de este, titulado campo de aplicación, de la siguiente manera:

“La presente ley se aplicará a la enajenación, total o parcial a favor de particulares, de acciones o bonos obligatoriamente convertibles en acciones, de propiedad del Estado y, en general, a su participación en el capital social de cualquier empresa.

La titularidad de la participación estatal está determinada bien por el hecho de que las acciones o participaciones sociales estén en cabeza de los órganos públicos o de las personas jurídicas de la cual éstos hagan parte, o bien porque fueron adquiridas con recursos públicos o del Tesoro Público.

Para efectos de la presente Ley, cuando se haga referencia a la propiedad accionaria o a cualquier operación que sobre ella se mencione, se entenderán incluidos los bonos obligatoriamente convertibles en acciones, lo mismo que cualquier forma de participación en el capital de una empresa".

La Ley 226 no es aplicable cuando la enajenación se hace en favor de otro órgano público. Tampoco aplica cuando la Nación enajena participaciones accionarias en las cuales su titularidad haya sido producto de un acto en el que no haya mediado su voluntad expresa o que provengan de una dación en pago, siempre y cuando esa participación no supere el 10\% del capital social de la empresa. En ese último caso, la Nación podrá, a su elección, enajenar la participación según el régimen societario al que se encuentra sometida la empresa o entregarla a la Cisa, para que esta última adelante la enajenación. (Bermúdez, 2018).

Frente a esta ley se encuentran debates sobre si es o no, eficaz y justa, puesto que se sostiene que el diseño de esta no ha favorecido a la democratización de la misma, y que por el contrario se hizo para privatizar, es decir transferir el control del estado al mismo estado en sí, teniendo como referencia que los encargados de las actividades estatales dentro de la política del país, son aquellos inversionistas con fuerza económica a quienes se les vende las acciones.

Para cualquiera es obvio que la venta del control de una compañía que nació como empresa estatal, y que por decisión de política económica se desea vender, es muy distinta a la venta de una participación minoritaria en una compañía controlada por particulares (El Tiempo, 2005)Si entramos al análisis de la ley como tal, cabe resaltar que a su vez es contradictoria en el aspecto donde en el artículo 4 se enuncia la necesidad de mantener un patrimonio público, en otro se busca la democratización pero con la intervención del estado al momento de colocar reglas en la compra y venta de las acciones, se les da prioridad a ciertos sectores nacionales, en la parte del procedimiento para la enajenación se puede caer en de manera apresurada en la fijación de un precio mínimo antes de dar inicio a la subasta de está impidiendo según grupos de economistas la maximización de los ingresos por parte del estado. 
Como resultado de todo este proceso los recursos son conservados por entidades privadas pero que a su vez tienen participación estatal, perjudicando así a la nación, sabiendo que el buen funcionamiento de esta ley ayudaría a mermar la deuda pública. A raíz de todos estos debates sobre cómo se desarrolla el artículo 60 de la constitución en la ley 226 de 1995, surgió una demanda de inconstitucionalidad contra los artículos 3, 8, y 23, todos parcialmente, de la ley mencionada, presentada el treinta (30) de mayo de dos mil doce (2012) por parte del ciudadano Luis Eduardo Castellanos Ávila con el Magistrado Ponente Nilson Pinilla Pinilla, en la sentencia C-393/12, este a su vez se apoya en la sentencia C-242/11.

Se demandó lo siguiente:

- Articulo 3...los fondos mutuos de inversión: los fondos de cesantías y de pensiones

- Articulo 8... presentarán el proyecto de programa de enajenación a consideración del Consejo de Ministros, el cual, previo concepto favorable, lo remitirá al Gobierno para su posterior aprobación.

...Debe ser presentado para su conocimiento al Congreso de la República durante los primeros 60 días del año.

- Articulo 23... El 10\% del producto neto de la enajenación de las acciones o bonos obligatoriamente convertibles en acciones... se invertirá, por parte del Gobierno, en la ejecución de proyectos de desarrollo regional en la misma entidad territorial, departamental o distrital en la cual esté ubicada la actividad principal de la empresa cuyas acciones se enajenen.

El ciudadano sostiene que el artículo 3 de la ley va en contra de los artículos 4 y 60 de la constitución política, ya que considera que al incluir los fondos mutuos de inversión y de los fondos de cesantías y pensiones dentro de los destinatarios de las condiciones especiales implica la vulneración o implícita modificación de ese precepto constitucional, puesto dentro de lo que se maneja como concepto de organizaciones solidarias y de trabajadores este tipo de instituciones no encuadran.

En el artículo 23 de la ley, se demandan dos partes de esta ya que van en contra de los artículos 151, 342, 347 y 359 de la Constitución Política, el problema radica en que si bien se postula que el 10\% del producto neto de la enajenación se invertirá en proyectos de desarrollo regional en el territorio donde la empresa realice sus actividades, por tal motivo modificaría las leyes anuales de presupuesto así como las aprobadas cada año en el plan de desarrollo y de una u otra manera regularían aspectos que deberían ser de ley orgánica.

Finalmente lo relacionado con el artículo 8 , estos se sostienen que son contrarios al numeral $9^{\circ}$ del artículo 150 constitucional, donde se establece que todo proceso de enajenación por parte del estado debe estar regulado por el congreso mediante ley, sino se da desacato al artículo 113, sobre separación de poderes, y $4^{\circ}$, en cuanto establece que la Constitución es norma de normas. Según explica, el hecho de que se establezca que la decisión de adelantar un programa de enajenación de acciones corresponde al Consejo de Ministros y que al Congreso basta con informarle sobre el llamado Plan de Enajenación Anual durante los primeros 60 días del año, vulnera directamente el referido precepto constitucional, que obliga a que este tipo de decisiones se tomen individualmente por parte del poder legislativo, mediante autorizaciones específicas. Por igual motivo, considera que la posibilidad de decidir la enajenación de la propiedad accionaria del Estado, mediante actuaciones propias de la Rama Ejecutiva y sin la participación del Congreso, vulnera el principio de separación de poderes (Sentencia C-393/12, parte III, demanda, 2012)

Respecto a la demanda se concluyó que los artículos demandados no van en contra de los artículos constitucionales, señalando que el primer artículo demandado no viola el presento se asociación solidaria puesto que estos se encuentran constituidos por trabajadores y solo ellos serían los beneficiarios, para el 
segundo artículo demandado se señaló que la Constitución no exige una autorización específica para cada operación de enajenación por parte del estado, y finalmente el último artículo demandado se determina que este no está sujeto a la reserva de ley orgánica.

Aunque a la final los tres artículos de la ley que fueron demandados se declararon exequibles, esto demuestra lo que podríamos denotar como desinformación que existe frente al tema de la regulación de procesos de enajenación por parte del estado, todo esto viene mucho más a fondo, iniciemos por enunciar que cuando se estaba a portas de la nueva constitución del 91, el pueblo se encontraba mucho más concentrado en los cambios políticos que podía tener el país a nivel interno, desplazando así su atención a los temas económicos como este, y por ende se conoce más sobre política que del funcionamiento económico del estado por parte de la nación, donde también se podría considerar que si bien muchos nacionales consideran que al ser entidades, empresas y/ o instituciones del estado colombiano, los dueños vendría siendo la nación, los ciudadanos, puesto que tiene la categoría de público, y es donde entra a jugar un papel clave el concepto de categorías a la hora de analizar los artículos constitucionales como bien es la posible consideración al pensar que muchos no consideran pertinente estas enajenaciones puesto que se le quita al pueblo para darle más poder y participación político económica a las oligarquías pudientes del país, pero si bien esto no es del todo cierto, todo tiene sus ventajas y repercusiones negativas, pero a la final existen demasiados factores externos que irrumpen con esta actividad.

Todo esto dilucidado hasta el momento nos lleva a la discusión referente al análisis sobre si el estado es bueno o malo accionante, para esto nos podemos trasladar a los inicios de los movimientos privatistas como el elemento central de la economía a mediados de los años setenta en Gran Bretaña, y que llego a Latinoamérica a mediados de los años ochenta con el afán de solventar la crisis fiscal por la cual se encontraban atravesando los países latinos. Todas las enajenaciones por parte del estado para mermar la crisis, más que todo fueron dadas para pagar deudas.

\section{Realidad social de la enajenación estatal del estado colombiano}

En los últimos diez años, el estado colombiano se ha venido quedando sin acciones y propiedades según los informes presentados por el periódico el tiempo, en este trascurrir se ha vendido aproximadamente el diez por ciento de Ecopetrol, una de las empresas con mayor crecimiento económico, la cual generaba grandes dividendos para el estado, donde por parte del congreso existen propuestas para seguir enajenando grandes porcentajes de esta empresa buscando cada vez más una mayor privatización en esta.

Otra de las grandes enajenaciones realizadas en los últimos años es la de la antigua Telecom, que se dio tras la declaratoria de la inviabilidad de la compañía durante el gobierno de Uribe y la creación de Coltel, la nueva empresa a la que le buscaron socios privados. La puja fue ganada por Telefónica, que ofreció capitalizarla con 369 millones de dólares y darle su conocimiento para el crecimiento de los negocios conjuntos, a cambio del 51 por ciento de las acciones (Manchengo, M. 2013)

Durante el periodo presidencial del actual senador de la república, el señor Álvaro Uribe Vélez, se vendieron alrededor de trece billones de pesos en acciones y empresas públicas, en sus ochos años de poder, se le aposto a la privatización de la mayoría de empresas publicas posible, Ecogas, Bancafé, Telecom, Granahorrar, Centrales Eléctricas de Norte de Santander y las electrificadoras de Cundinamarca y Santander fueron unas entidades vendidas, al igual que en el mandato de su sucesor, el ex presidente Juan Manuel Santos, con la enajenación de la empresa Isagén. 
A todas estas ventas se suman la modificación del personal en 93 organismos y entidades del estado entre las que se cuentan Findeter, la Fuerza aérea y el ejército. En total, entre restructuración, venta, liquidación y reformación, fueron cerca de 500 empresas estatales (Las2orillas, 2016)

Antes de culminar el periodo presidencial de Santos, se inició la venta de 32,5\% de las acciones que tenía el estado en la empresa Coltel, las empresas más grandes de telecomunicaciones de Colombia, fusión de Movistar y Telecom. En su momento esta enajenación estaba en manos del ministerio de hacienda, se realizaron estudios por parte de la banca de inversión en el proceso de telefónica desde el Bank Of América de New York. Con el empalme del actual gobierno del presidente Iván Duque se dejó de lado, sin una razón, la venta de Coltel, ya que al ser analizados los planes de venta esta no aparece, una de las posibles hipótesis acerca de esta exclusión, es la falta de compradores necesarios para iniciar una subasta de las acciones, puesto que hasta el momento fue conocido un solo inversionista.

Actualmente el estado se encuentra dando importancia a la venta de ISA, en un cincuenta y uno por ciento, el cual es un activo rentable, siendo un negocio de energía sin problemas a futuro que genera ingresos al estado, a diferencia de la empresa anteriormente mencionada. Este gobierno busca la privatización de las empresas para así obtener un aproximado de seis billones de pesos por año para ser invertidos en activos que generen mucha más rentabilidad para el estado.

El director de Crédito Público del Ministerio de Hacienda, César Arias, (2019) sostiene que la participación del Estado en las más 100 empresas públicas y privadas tiene un valor estimado en 25.000 millones de dólares y que el año pasado generaron una rentabilidad de alrededor de 4.000 millones de dólares, que calificó como «muy baja»

A raíz de todo lo dilucidado, el congreso a pesar de aprobar el plan de desarrollo, se encuentra dividido a la hora de enajenar empresas como Ecopetrol, ya que es considerada como una compañía líder que genera grandes ingresos para el país.

\section{El pago de la deuda externa del estado Colombiano a los Estados Unidos de America}

El gigante federalista como lo es los Estados Unidos de América después de la gran coyuntura de la primera guerra mundial los préstamos, es decir, el crédito pasó diferentes etapas debido a las variantes en las fuentes de sus financiamientos. Durante la primera fase, de enero de 1915 a abril de 1917, los préstamos internacionales se basaron en los mercados de capitales privados de los Estados Unidos. El endeudamiento de los Aliados en los Estados Unidos se elevó al ritmo de los crecientes requerimientos de municiones y alimentos. (Mauricio, 2003). Todo esto es justificado por el hecho de que los préstamos, todos en su mayoría, fueron colocados por los países de los cuales este era aliado, donde el restante, una minoría en realidad, se orientó a los estados latinoamericanos, estos créditos tenían la categoría de corto plazo puesto se encontraban inmersos en una realidad de guerra fijándose en términos considerados como muy liberales. La segunda fase, transcurrida entre abril de 1917 y mayo de 1922, se caracterizó por la implementación de las leyes del Crédito de la Libertad de acuerdo con las cuales el Gobierno de los Estados Unidos fue autorizado para adquirir obligaciones externas de los gobiernos aliados (Mauricio, 2003), algunos años antes que sucediera la caída de la bolsa de valores de Nueva York, donde en ese tiempo se inició el resurgimiento del crédito privado, encontrándonos a nivel internacional con el crédito Dawes y las leyes de préstamo de crédito de la libertad. 
Bajo los últimos mecanismos mencionados los gobiernos extranjeros podían comprar bonos, mediante un vínculo indirecto con el estado americano, como lo fue el caso de Colombia, los cuales estaban denominados en dólares en el capital interno, hasta que se estableció el empréstito Dawes, enriqueciendo las oportunidades de inversiones y volcándolos a vínculos directos. Lo que debe subrayarse en este punto es que la internacionalización de las inversiones privadas de los Estados Unidos rebasaría las fronteras alemanas y europeas formando oleadas crediticias sin precedentes, las cuales alcanzarían las costas de América Latina, Australia y el Japón. (Mauricio, 2003).

La realidad en el caso colombiano, es que este en los últimos cuarenta años el pago de la deuda externa del país no ha sido motivo de preocupación, a excepción del caso vivido durante la finalización del gobierno presidencial del general Rojas Pinilla donde durante las crisis económicas de los años 66 y 67 busco el apoyo de banqueros internacionales por 25 millones de dólares, pero estos denegaron la ayuda, generando así para los años 70 una deuda incluso mayor en relación con los años 30.

Los países del Tercer Mundo tienden a endeudarse alegremente. Es más sencillo recurrir al capital financiero internacional que crear nuevos impuestos al ingreso. Sin embargo, las dificultades aparecen y se agudizan cuando los nuevos flujos se estancan durante los períodos de recesión internacional: el capital financiero se caracteriza por su volatilidad, y el pago de la deuda por su rigidez. (Echavarría Soto, 1982). Los cambios en referentes al capital llenaron Sudamérica durante los años veinte, pero estos se acabaron completamente luego de la gran depresión en 1929, atormentando a estos países de una forma mucho más perspicaz con respecto al resto de los países del mundo, y al no bastar solamente con lo anterior, también cayeron los precios de los productos agrícolas y primarios, mientras que a los agricultores norteamericanos se les permitió el no pago de la deuda, al resto de los países sudamericanos se iniciaron procesos moratorios por el incumplimiento de los mismos.

Según Olaya, la moratoria sería perjudicial. Siempre consideró factible la posibilidad de atraer nuevos préstamos de largo plazo. El que la Depresión no golpease tan duramente la economía colombiana, y que el precio internacional de nuestros bonos hubiese aumentado nuevamente en 1932, llevó al gobierno a un excesivo optimismo no compartido por otros países latinoamericanos. (Echavarría Soto, 1982). Un factor especifico con respecto al caso colombiano, es la gran confianza que se tenía con respecto a las compañías extranjeras aplicándose parcialmente a los intereses generados por estas mismas en el sector petrolero. Todo este proceso moratorio tardío en el país se encuentra sumergido en que a diferencia de otros países sudamericanos, este no conto con ningún golpe de estado durante la gran depresión generado por militares nacionalistas que al llegar al poder tildaron como culpables el gobierno liberal con respecto a las altas tasas de deudas.

A pesar que los conocedores en el tema determinan que la capacidad estatal ha sido importante para el aumento de la economía, cabe resaltar que en los años veinte no se consideraba, erróneamente, importante conocer cuál era la cantidad de divisas que reintegraban las multinacionales, donde el gran flujo de aportes capitales que llegaron en el país en esta década, fue un determinante para la trasformación económica del país, mucha de estas orientadas a la mejora continua de factores externos que afectaban directamente la economía del país como la creación de carreteras adecuadas para la exportación de materia prima, como lo es el café, permitiendo en un futuro el pago de la misma deuda, también sacando ventaja de coyunturas en otros países para el no pago de las deudas como lo fueron la guerra con el país de Perú y la suspensión del sistema de valorización en Brasil.

En cierta medida las ventas realizadas de las empresas estatales a personas naturales o jurídicas que no se encuentren participes en otra entidad del estado, han ayudado a pagar la deuda externa del país 
con respecto a los Estados Unidos, ya que todo llega a un mismo deposito, a los fondos estatales. Si bien, encontramos diferentes puntos de vista referentes al tema sobre lo que se debe y no se debe hacer con el dinero de estas enajenaciones, surgiendo conflictos de intereses de aquellos que están en contra de la privatización y los que estén a favor, por lo cual el estado cuenta con expertos economistas para el estudio de la solución que estos consideren la correcta para el aprovechamiento de los fondos monetarios.

Pero hay más cosas sensatas que se pueden hacer con esos fondos. El mismo economista había propuesto hace un tiempo que se vendiera el 10\% de Ecopetrol para pagar la deuda externa nacional. La idea sigue siendo válida hoy y serviría, dice, para ampliar el espacio que tendría en el presupuesto el gasto en seguridad y el gasto social. Además sería casi seguro que Colombia obtuviera su grado de inversión y con eso podrían bajar los intereses en los préstamos a la Nación de ese momento en adelante. (Revista Electronica Dinero, 2010)

\section{Conclusiones}

La gran depresión de 1929, conllevo a una quiebra financiera sin precedentes en la historia económica mundial por la mala manipulación económica por medio de créditos sin garantías, donde las familias se endeudaron por arriba de su patrimonio aceleraron la caída de la bolsa de valores. En América Latina no todos los países se vieron afectados a gran escala, pero si los que dependían de la industria pesada, y del crédito capital inyectado por los bancos norteamericanos, lo cual paralizo a la obras en todo el continente de américa del sur. La agricultura en las zonas rurales decayó, por ende se vio aumento el desempleo. En el caso colombiano la depresión dio pie para generar un avance económico, como respuesta al duro momento financiero que se estaba atravesando.

La apertura de la economía colombiana al mercado mundial en los noventa dio paso a la renovación de la manera en cómo se llevaba el poder de las empresas al interior del país, buscando privatizarlas quitándole en cierta medida un peso al estado, se iniciaron enajenando monopolios de empresas de telecomunicaciones, energía, entre otras. Por esta manera el estado no solo debe verse como tal, sino también como una empresa y por tal motivo debería contar con un plan de administración eficaz sobre las empresas en las cuales tiene acciones, porque de una u otra forma, la nación se ve beneficiada de los dividendos.

Las políticas del estado colombiano para la enajenación de las acciones estatales, reguladas por el artículo 60 de la constitución y en la ley 226 del 95, relacionado con el movimiento privatista de las empresas, trata de políticas económicas influenciadas por entes internacionales, donde entra el dilema de si el Estado es bueno o malo para el manejo de acciones estatales enfrentándose al desafío de ser un buen accionante, para esta regulación se plantean objetivos económicos para buscar el rendimiento adecuado del capital que el estado colombiano tienen invertido en cuyas empresa es participe, se resalta la manera por la cual se busca la separación del estado con las funciones de accionista que tiene de otras actividades estatales.

Cuando el Estado es accionista de alguna empresa, este no es concebido como el ente del estado como tal, sino que dentro del imaginario comercial y económico, este pasa a ser un accionista ordinario implementándose las normas de derecho comercial, por tal motivo es de suma importancia reconocer las diversas situaciones, ya que la participación del estado en todas las empresas en las cuales tenga derecho, no serán iguales, es decir, hay empresas que cuentan con acciones de mayoría estatal, mientras que en otras no, en otras encontramos una economía mixta, dándose una mezcla de derecho público y derecho privado. 


\section{Referencias Bibliograficas}

Amadeo, K. (2020). Amadeo, Kimberly, The Worst Crash in U.S. History, Stock Market Crash of 1929 Facts, Causes, and Impact. Retrieved from the balance website: https://www.thebalance.com/stockmarket-crash-of-1929-causes-effects-and-facts-3305891

Bermúdez, D. (2018). Enajenación de Propiedad Accionaria Estatal. Asuntos: Legales.

Bulmer Thomas, V. (1990). Historia de América Latina, economía y sociedad desde 1930, primera parte economía, las economías latinoamericanas 1929-1939. España: cambridge university press critica.

Echavarría Soto, J. J. (1982). La deuda externa colombiana durante los 20s y los 30s. Algunas enseñanzas para el presente. Universidad de Oxford, En St .Antony's College.

El Tiempo. (2005, March 28). la venta de acciones del estado. El Tiempo. Retrieved from https://www. eltiempo.com/archivo/documento/MAM-1637958

Ley 226 de 1995

Mauricio, A. G. (2003). Antecedentes Históricos de la Deuda Externa Colombiana De la Paz Británica a la Paz Americana. Bogotá: Estudios Económicos del Banco de la República.

Constitución de Colombia de 1991

Revista Electronica Dinero. (2010, March 26). El Estado en venta. Dinero. Retrieved from https://www.dinero. com/economia/articulo/el-estado-venta/93385

Rodríguez, A. L. (2011). Crisis de los años treinta e impacto en América Latina, Rodolfo Iván González Molina. Facultad de Economía-Universidad Nacional Autónoma de México, 43(168).

Sentencia C- 393/12, Corte Constitucional

Throp, R. (1988). el efecto de la gran depresión de 1929 en las economías de Colombia y Perú, fondo de cultura económica. In América latina en los años treinta, el papel de la periferia en la crisis mundial (p. 388). México: Fondo de Cultura Económica. 